\title{
Future lighting and the appearance of cities at night: A case study
}

Future lighting solutions based on solid-state lighting will transform the appearance of cities at night. They can be positioned and used in an urban environment in numerous ways. This article studies whether their future use in general outdoor lighting will positively affect people's acceptance of urban space illuminated in this way. Two different lighting concepts were formed based on the innovative use of solid-state lighting solutions. The first concept is based on plane lighting, and the second is based on a detailed depiction of architectural and urban elements. Lighting proposals were designed for five different city locations. They consider not only functional needs, but also urban planning and the architectural aspects of illumination. I present my study of the underlying core effects on the respondents through their assess- ment of the affective quality of graphic representations. My findings indicate that the respondents strongly agree with the assessment of the "pleasantness" and "arousal" variables of most proposals. However, the statistics show characteristic differences between the answers of both variables for both concepts. Direct comparison of the two concepts shows that the respondents' attitudes towards a certain lighting concept also depend on their location in the city. This article emphasises the importance of the appearance of a city at night in developing future lighting strategies based on solid-state light sources.

Keywords: LED, OLED, lighting design, appearance of urban spaces at night, Ljubljana 


\section{Introduction}

Quality outdoor lighting and signage lighting are key to both the night-time and daytime design of modern urban environments. Contemporary urban lighting design involves holistic light planning. In addition to the importance of functionality, cost, maintenance, light pollution and energy use, the architectural, aesthetic and emotional value of such proposals should also be considered. Although visibility is an important factor of quality illumination, it was often placed at the forefront of efforts and other aspects were overlooked. Diana Joels (2006) notes the increased prevalence of the aim to create harmonious lighting that is appropriate for its environment and sensually illuminates its context. Considering the principles of sustainability, in addition to environmental and economic aspects, one should also consider enhancing the appearance of spaces as well as establishing the social engagement and wellbeing of city residents (Casciani \& Rossi, 2012). In the near future, solid-state lighting (SSL), which also includes light-emitting diodes (LED) and organic light-emitting diodes (OLED), is expected to help address the challenges posed by urban lighting. SSL technologies have great promise due to their technical capacities, energy efficiency and ongoing rapid development. The new possibilities of including LED and OLED lighting in the built structure of cities offer additional functionality and are creating new design frameworks. Despite the fact that LED-based technology is rapidly gaining a foothold in the share of fixtures used in outdoor lighting, the mass use of OLED lighting in urban spaces is still some years in the future. LED and OLED lighting technologies can be used in many different ways, including innovative positioning in the built structure of a city, creating new combinations of lighting features with different intended uses, adapting lighting to weather conditions and the presence of users, lighting interactivity and new applications for informative and decorative purposes and orientation. This may significantly affect the appearance of cities at night. The main question this article addresses is whether the future possibilities of using LED and OLED luminaires in general outdoor lighting can positively affect people's acceptance of urban space illuminated in such a manner. To this end, I designed a plan concept and a detailed concept of future lighting, and visualised them in a case study of five locations in Ljubljana. My aim was also to verify which lighting illumination concept was more pleasant and more eye-catching than others in each selected location. The article then studies respondents' opinions regarding the aesthetic aspect of the lighting proposals, their visual orientation in the proposed spaces and the suitability of the lighting proposals for each relevant location. The underlying aim was to develop guidelines for the reasonable positioning of LED and OLED luminaries in urban spaces. Research on the illumination of urban spaces, based on appearance stimuli, has also been conducted in recent times, but mostly relates to existing lighting options (Ünver, 2009; Casciani \& Rossi, 2012). In recent times, many research projects have studied various elements of human perception of outdoor spaces at night (Johansson et al., 2011) and have also compared various light source technologies (Rea et al., 2009). Studies of LED luminaries have also investigated the perception of quality of lighting, visual accessibility and the feeling of danger, either by using LED retrofits in existing luminaries (Kuhn et al., 2013) or comparing LED sources with conventional light sources (see, e.g., Kostic et al., 2013). However, little attention has been paid to the future potential uses of solid-state lighting and the subsequent potential changes to the appearance of urban spaces. This article fills this research gap and studies the impact of such changes on the appearance of a city. I also present the various problems posed by placing LED and OLED luminaries in an urban environment. At the same time, I highlight the fact that the importance of the appearance of cities at night should be considered when adopting new lighting technologies. The article first briefly presents architectural and urban planning aspects of lighting, describes LED and OLED lighting and discusses the impact of illumination on people's emotional reactions. It then focuses on research methods and provides an overview of proposals for future lighting. The presentation of results is followed by a discussion on whether the proposed solutions are justified and acceptable, which also provides guidelines for further research.

\section{Theoretical grounds}

\subsection{Architectural and urban planning aspects of illuminating cities}

In the literature, outdoor lighting is usually categorised as either functional (pursuing the interests of visibility and safety) or decorative (i.e., lighting used to create an appropriate city appearance). Urban spaces are increasingly frequently used during the evenings into the late hours of the night for various cultural, social, sports and entertainment activities that people cannot take part in during the day due to work commitments. Any artificial lighting should not impair the city's appearance at night. A city's lighting should also attract people to cities, direct them and enchant them (Brandi \& Geissmar-Brandi, 2007). Ulrike Brandi and Christoph Geissmar-Brandi (2007) believe that the architectural idea of "another" night-time city is a key architectural and urban planning aspect of illuminating any city. Light usually allows people to experience any space, thus making lighting design an important architectural component. Joels (2006) emphasises that lighting is a crucial factor in improving the harmony between functional and visual statements in the urban context. One of the aims of urban lighting is to establish essential characteristics of an 
urban identity, which is increasingly less certain today. Appropriate illumination is also one of the key principles of sustainable streetscape design (Rehan, 2013). Alexander Schmidt and Martin Töllner (2006) explain that light can be purposely used to exclude anything people deem unpleasant or incorrectly highlighted in the environment, giving the appearance of the city at night a positive psychological impact. Tomaž Novljan (2008: 90) introduces the term "architectural ambiances degraded by illumination" to denote a specific level of space in architecture at which inappropriate illumination impairs the perception and use of an otherwise well-designed built space. He believes that overpowering or undifferentiated lighting of quality architectural elements and components can negatively affect and degrade the design of an otherwise quality lighting ambiance. Reflected light, shadows, structure, textures and the colour of illuminated buildings play an important role in this (Novljan, 2008). Urban lighting should conform to the urban lighting master plan, which should combine innovation and sustainable energy policies with aesthetic enhancement of urban space, and with respect to which environmental factors should also be considered (Schmidt \& Töllner, 2006). More generally speaking, these are the challenges of urban management (see, e.g., Bačlija, 2011).

\subsection{LED and OLED lighting}

LED and OLED light sources are based on solid-state lighting technology and allow for various lighting effects. The individual chips used by an LED light source are usually small. When used in general lighting, LED components are combined into a system, which usually comprises corresponding optics. OLED components are usually larger and are "surface" light emitters. Despite the fact that today these two technologies complement each other, they may compete against each other in the future (Hohl-Abi Chedid, 2012). Both promise less energy consumption and less maintenance, and that they will transform lighting infrastructure. Solid-state light source technology carries the idea of a "digital light paradigm" (Kennedy, 2005). This technology is no longer part of the "lamp culture" in lighting, but offers a new digital light model, thus shifting the balance between light and information. This differs from the categories established by design professionals and offers a new manner of thinking about materials. The innovative positioning of SSL in urban spaces also makes it possible to blend functional lighting and lighting used to enhance the city's appearance. Familiarity with the characteristics of such technologies is paramount for their effective positioning in urban spaces in an environmentally friendly manner. LED technology has already entered the mature stage of development. Forecasts of the market share of LEDs in outdoor lighting show an increase from 6\% in 2011 in Europe, Asia and North America to over 70\% in 2020 (McKinsey, 2012). Different forecasts have been made for OLED lighting. Although OLED lighting is in an intensive phase of development as a general lighting solution, it is fairly difficult to predict its future (see, e.g., Parandian \& Rip, 2013). Some believe that OLED lighting will only have a marginal role in general lighting by 2020 , whereas others believe that 2020 will signify the beginning of its widespread use in all areas. OLED technology is based on active organic layers that use the advantage of thin-film transistor performance for its operation. Flexible substrate technology can be used to make thin, flexible and transparent light sources. Such luminaries can be built into materials or architectural surfaces. Developing the technology to a level that enables the uniform luminance of OLED light sources is also very important in this respect (Slawinski et al., 2013). Emphasis has also been placed on studies of the models of mechanical characteristics of flexible OLED devices (see Chiang et al., 2009), on studies of the optical characteristics of transparent OLEDs (Lee et al., 2011) and the relevant cooling of OLEDs in operation (see, e.g., Schwamb et al., 2013). Vapour and oxygen in the air cause the rapid deterioration of OLED devices, making protection of the organic layers a major priority. In this respect, organic thin-film encapsulation with a vacuum thermal evaporation technique shows good potential (Grover et al., 2011). In the near future, solid-state lighting based on lasers may also complement LED and OLED lighting. It could allow high potential efficiencies even at higher current densities than can be achieved with LED and OLED technologies. Tests have also demonstrated that, despite their narrower spectral linewidth, lasers using different wavelengths of light could generate white light appropriate for general illumination (Neumann et al., 2011).

\subsection{Studying the effect of lighting on human emotional responses}

The interaction between humans and their physical environment depends on each individual. The circumplex model of affect developed by James A. Russell (1980) as a framework for studying environmental impacts on emotional response assumes that affects and emotional states can be best described by two main dimensions: arousal and valence. According to Russell (2003), the core affect is the first elementary foundation in the psychological interpretation of emotions. The core affect is the neurophysiological state the person consciously experiences at any given moment and is thus simple and non-reflective. Emotions emerge from such core affects. The valence level ranges from extremely positive to extremely negative, and the arousal level ranges from relaxed to excited. Geometrically, the structure of emotional states can be represented by a two-dimensional grid, with the level of arousal and level of valence on each of the two axes. According to Russell (2003), perceiving pleasant or unpleasant qualities, and activating or deactivating qualities of external triggers (stimuli) 
such as buildings, places and events, is the second elementary foundation in the psychological interpretation of emotions. He refers to this as the perception of affective quality. Whereas the core affects are the internal emotional states of the person in question, affective quality is the property of the stimulus that can trigger a change in the core affect. Affective quality is usually measured with the same two dimensions as the core affect. Ahmet Ünver (2009) states that light is one of the most important factors that helps create the appearance of built environments and affects how people experience urban spaces at night (Mahnke, 1987; Narboni, 2004; Ritter, 2006). Rikard Küller et al. (2006) found that the subjective quality of lighting affected people's moods more than illumination as measured in objective terms. Psychological procedures allowing the assessment of subjective feelings and experiences in research on illumination and the use of various assessment methods, such as semantic differential scales, were developed as early as the 1970s (Flynn et al., 1979). Maria Johansson et al. (2011) emphasises that subjective judgments of brightness and the perceived level of pleasantness of an illuminated space are the two most important elements that determine the subjective quality of lighting. Tools used to assess the quality of lighting have also been developed on this basis (Johansson et al., 2013). Discussions and studies of what information pictures of objects or an environment can provide compared to the real world have been an important focus of the psychology of perception for several years. Although James Gibson's (1971) theory distinguishes between depictions of and the direct perception of features of the environment, he emphasises that there is common information for the characteristics that both have in common. John M. Kennedy (1974) also summarises that light can "carry information" and presents various theories of how images can provide the observer with information. He emphasises that familiarity with philosophy, physics and psychology is needed to understand how people perceive objects through images. Although images can be a useful research tool, one must bear their limitations in mind.

\section{Method of research}

An online survey was designed in order to obtain data on the perceived, cognitive and emotional impact of an illuminated night-time space on individuals. Combined with Web 2.0 tools, such a manner of electronic public participation allows for easier involvement of the public in planning procedures (see, e.g., Bizjak, 2012). Graphic representations of the future lighting of selected Ljubljana locations were displayed in the survey. I followed Daria Casciani and Maurizio Ros-

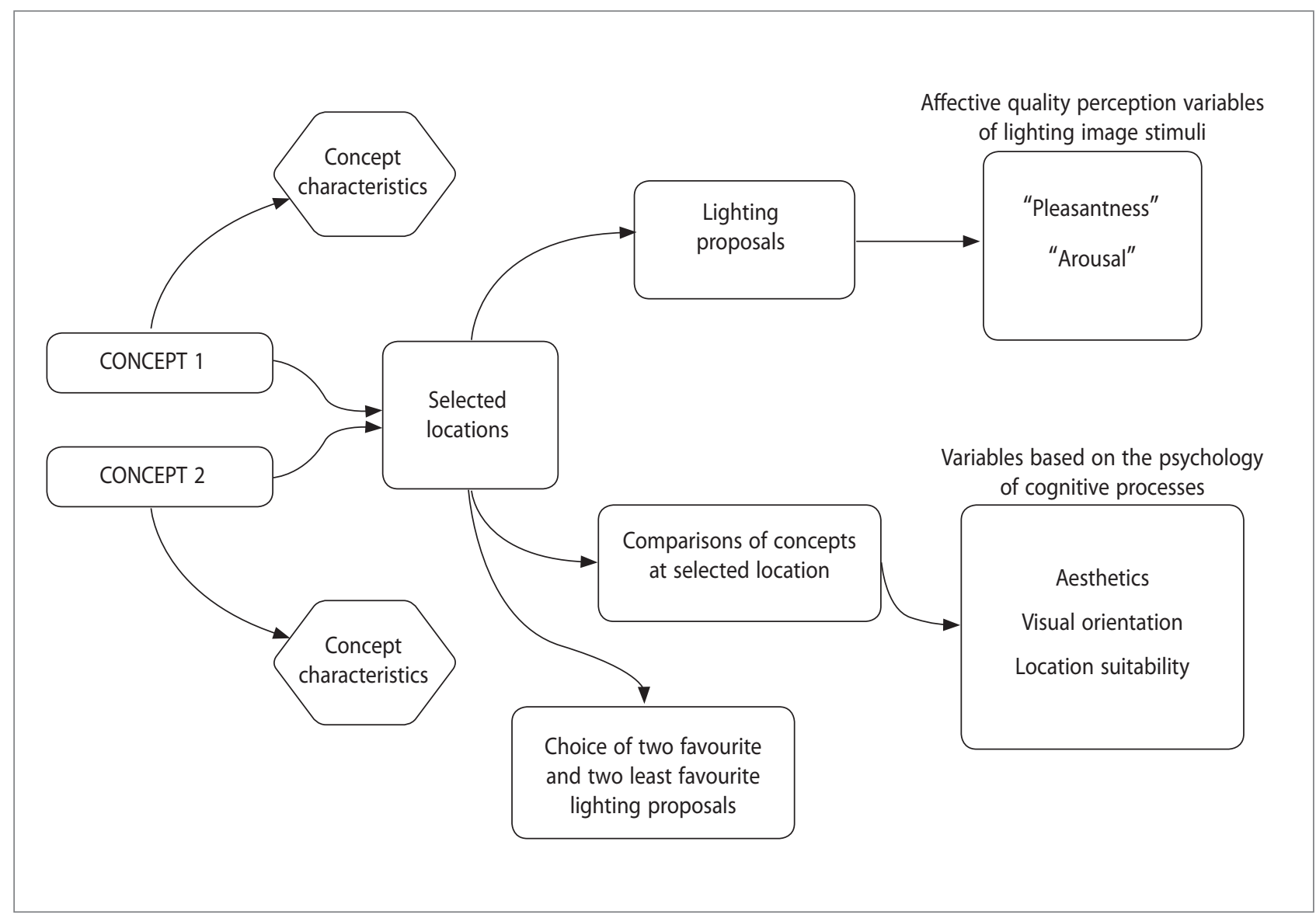

Figure 1: Overview of the research model used in the online survey (illustration: Simon Rankel). 
si (2012) in selecting "pleasantness" as a feeling experienced by the respondents upon observing the lighting proposals and "excitement" or "eye-catching" as the interest of the respondents in each lighting proposal as the variables determining the arousal and valence dimensions according to Russell's model. These two variables determine the affective quality of the images of the lighting proposals and thus influence the core affects of the respondents. The "eye-catching" variable is more briefly referred to as "arousal". The questions in the online survey were used to measure the level of agreement or disagreement on the part of the respondents with the "pleasantness" and "arousal" of the lighting proposals. Using both indicators and a two-dimensional model of emotional states, I designed a variable to measure the level of impact; namely, how people experience illuminated urban spaces. The individual future lighting proposals for the various locations are the major predictive variables used in the study. In the second part of the survey, I directly compared both concepts for the same city location. In doing this, I defined variables based on the psychology of cognitive processes. These variables were used to study respondents' opinions with respect to the aesthetic aspect of the proposed lighting, its visual orientation in the proposed spaces and the suitability of the lighting proposals for each location (Figure 1). The respondents' opinions on the appropriateness of each lighting proposal do not necessarily match their aesthetic assessment. The "visual orientation in an illuminated space" variable refers to the ability to experience urban spaces and their clarity (Schmidt \& Töllner, 2006) and is closely linked to the concept of legibility as defined by Lynch (2010). The ability to read house numbers and street names is also part of orientation and can, to some degree, be linked to the concept of visual accessibility of a space. This is defined as the effectiveness with which one's vision can be used to safely navigate through the space (Legge et al., 2010). I also asked the respondents to specify their two favourite and their two least favourite illuminated urban space scenes. This was used to verify whether the location would decisively affect the respondents' choices of their favourite scene and consequently also their opinion of the "pleasantness" and "arousal" of each lighting proposal. I intentionally placed this question at the end of the survey.

\subsection{Data collection and the research sample}

Data were collected using a structured online survey. The five-level scale used to assess statements in the first part of the survey was treated as an interval scale. I achieved this by allowing respondents to give an answer from 1 to 5 reflecting their degree of agreement with each statement $(1=$ completely disagree, $2=$ disagree, $3=$ undecided, $4=$ agree, $5=$ completely agree). When asked to directly compare both concepts, respondents were given only three possibilities: to choose either concept or to answer that both concepts are no different with respect to the variable in question. The online survey was open for three weeks in October 2012. The survey was made available through a link that was sent to various groups of people via e-mail. The link was also sent to various Facebook groups and to 550 Slovenian architects and selected lighting designers.

\subsection{Location selection and their characteristics}

Five locations inside the Ljubljana ring road were selected. They include typical urban elements such as roads and footpaths, buildings, bridges, squares, service areas, parking lots, parks and landscape elements. The selected locations differ in terms of how the space is utilised, which can overlap in some locations. The first three locations are the area along Maria Saal Street (Gosposvetska cesta), the Ajdovšcina neighbourhood and Slovenian Reformation Park (Park slovenske reformacije). These locations are intended for residential, administrative, service, educational and cultural facilities. All three locations lie at important crossroads from the business centre of the city to traffic, retail and service locations. According to regulations governing the protection of cultural heritage (Prosenc \& Potočnik, 2011), part of this area is protected as cultural heritage. The fourth location is Trnovo Quay (Trnovski pristan) along the Ljubljanica River. The Hradecky Bridge (Hradeckega most) that connects the city centre to the Gruden Embankment (Grudnovo nabrežje) in the Prule neighbourhood was also covered by the proposal. This location is occupied by residential and service facilities, and is at the same time one of the points of entry into the central tourist area of Ljubljana's city centre. The bank of the Ljubljanica River beginning at Trnovo Quay and ending at Špica Point is an important city promenade and, as a connecting structure, is a fundamental element of the city's recognisable structure (Sašek Divjak, 2008). Young people gather on the riverbank in summer evenings. The fifth location is a typical residential building and walking path in the Sava Housing Estate (Savsko naselje). The Sava Housing Estate is a residential neighbourhood with many residential buildings, high-rises, parking lots and garages and is located near the city centre, close to Ljubljana Hospital and the railway station. I chose scenes that define each location as best as possible. Generally speaking, the glare of luminaries and light trespass are the most disturbing aspects of Ljubljana's illumination. The city centre billboards are too bright, the appearance of Ljubljana's main streets at night is not well thought out, and spaces along the junctions of major roads are too bright. In some locations, pedestrian crossings are too dim, and the use of correlated colour temperature of light sources is inconsistent. The illumination of road signs is too inefficient and most luminaries cannot be regulated. My analysis of the existing lighting at each location shows that, despite some recent improvements introduced as a result of regulations limiting light pollution, 
the existing lighting is still inappropriate in many respects. The appearance of the city at night has been overlooked in most of the locations discussed. Little planning has been applied in some of the attempts to correct this. Trnovo Quay is a part of the city that its inhabitants are very fond of. Here, improved but discrete illumination could contribute to enhancing the appearance of this part of the city. In the case of the Ajdovšcina neighbourhood and Maria Saal Street, any lighting should attempt to contribute to reinforcing the importance of these two locations, which "once had a much more specific character than nowadays" (Bandur, 2012). In Ljubljana's residential neighbourhoods, enhanced lighting could contribute to the residents' improved wellbeing and could revitalise older and less attractive neighbourhoods. Emphasis should be placed on sensual and discreet lighting that is in operation only when needed. This would ensure that residents can rest at night but also provide a pleasant view of the residential neighbourhood.

\subsection{Future lighting concepts and representations}

Using daytime photographs of the current state, I designed two future lighting concepts for each of the five locations selected. The photographs were taken in the spring and summer when there was no precipitation. Both lighting concepts are intentionally quite clearly different and take into consideration certain urban design criteria. Both concepts take into consideration the visual requirements of functional road and path lighting. Both concepts also emphasise the distribution of light and reducing any unintentional trespass, reducing glare and enhancing the view of the city. The first concept is referred to as the plane concept, and the second is referred to as the detailed concept. The first emphasises the uniform plane illumination of space and has large but not overly bright luminous surfaces. This involves installing luminaries on the façades of houses and the walls of buildings, and building them into the ground. In some locations, such luminaries have both an ambient and functional meaning. Luminous cycle paths and pedestrian crossings are also important for safety reasons and for information orientation. My lighting proposals avoid exaggerated ground contrast, which could disturb elderly residents or visitors. The detailed concept emphasises a blending of light and dark, creating an urban rhythm and revealing appropriate light contrasts. Hidden architectural elements that are not supposed to be visible at night are therefore not illuminated. I seek to emphasise and recognise the differences in the built urban structure and selected details, as well as to re-establish lost links. The emphasis is on using LED and OLED luminaries in architectural elements such as windows and edges. Information boards and signs are clear and well visible. Generally speaking, this concept is less bright than the plane concept. In both concepts, the architectural elements and built urban structure remain unaffected. Only minor changes to urban elements can be anticipated. In both concepts, advertising billboards and shop windows are lit discretely, ensuring that they do not stand out, and signs, signposts and information boards are easily visible. The illumination of advertising billboards and shop windows does not aim to "compete" with ambient urban lighting. In both concepts, bars and restaurants are also illuminated discretely. Thin translucent OLED luminaries on the façades of a select number of buildings would have no impact on the daytime appearance of the city. Any such positioning would have to conform to the principles of balanced urban renewal strategies (Ho et al., 2012). Such luminaries could be combined with hybrid lighting systems (see, e.g., Mayhoub \& Carter, 2012), which simultaneously use daylight and artificial light sources in indoor lighting. Some buildings in the locations discussed are protected as natural or cultural heritage. This applies to the façades of buildings along Maria Saal Street, certain elements of Slovenian Reformation Park and some buildings at the Ajdovšcina location (Sln. Odlok o razglasitvi spomenikov naravne in kulturne dedišcine na območju občine Ljubljana Center med Aškerčevo, Tivolsko in Slovensko cesto, Ur. I. RS, no. 60/1993). According to law, the entire façade of buildings facing Maria Saal Street is protected. The Cultural Heritage Protection Act (Sln. Zakon o varstvu kulturne dedišcine, Ur. l. RS, no. 16/2008) specifies that the architectural structure of façades cannot be interfered with (i.e., destroyed). Thus approval of the body tasked with protecting cultural heritage would be needed in order to affix transparent OLED luminaries. OLED luminaries could also be installed on the windows of selected buildings. This would allow the windows to function as normal during the day and to act like blinds at night. The window exteriors would emit a cosy light. If such a window were opened at night, the luminous blind would gently turn off. Certain LED and OLED luminaries emitting monochromatic light could be used especially for temporary decorative purposes. Carl Gardner (2006) notes that caution is needed when using colours outdoors. The findings of the research conducted to date on the impact of colours on human behaviour and perception of the environment (see Ab Jalil et al., 2012) are also important. When designing permanent outdoor lighting, it is important to apply an appropriately correlated colour temperature of white light sources and also to consider their spectral distribution. Some LED and OLED luminaries allow their correlated colour temperature to be controlled in many different ways (Kim et al., 2012). Transparent OLED devices could be used to highlight road signs such as pedestrian crossings, cycle paths and kerbs. Such use would have to be well thought out from the perspective of traffic safety and visual perception. In my opinion, it would make sense to use OLED and LED luminaries to highlight house numbers and street names, which are especially difficult to see at night. The graphic representations show a great level of detail, such as street names on the façades of houses, luminous house num- 

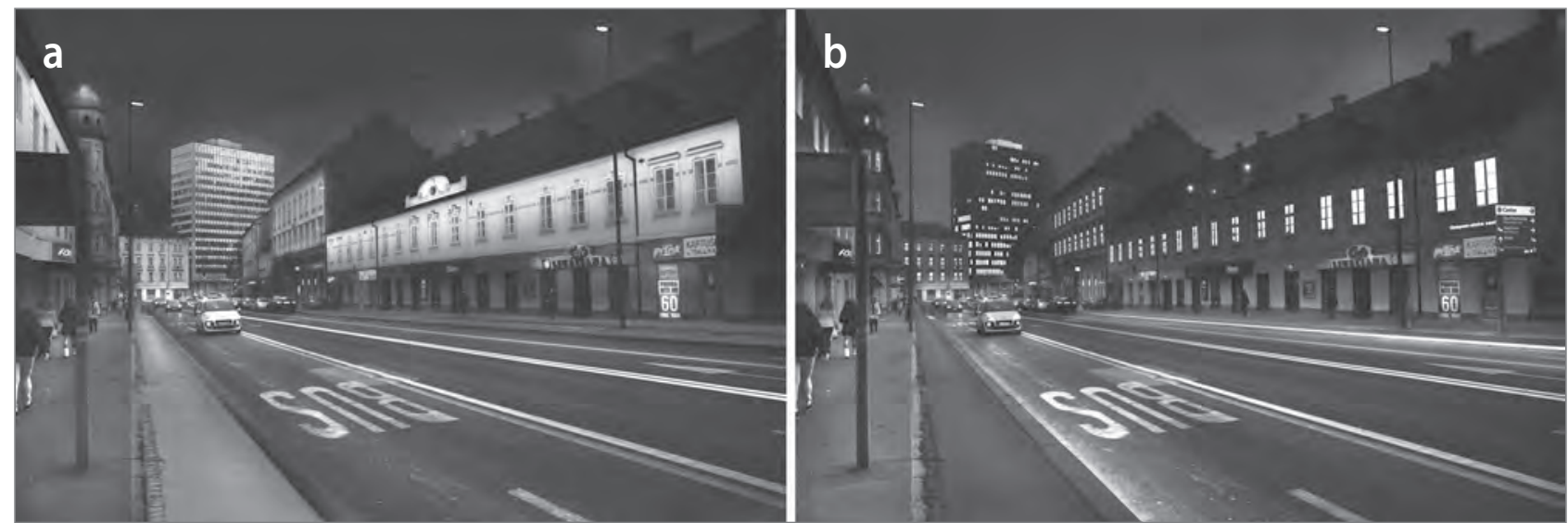

Figure 2: a) Maria Saal Street, GK1 plane concept, b) Maria Saal Street, GK2 detailed concept (photo and design: Simon Rankel).

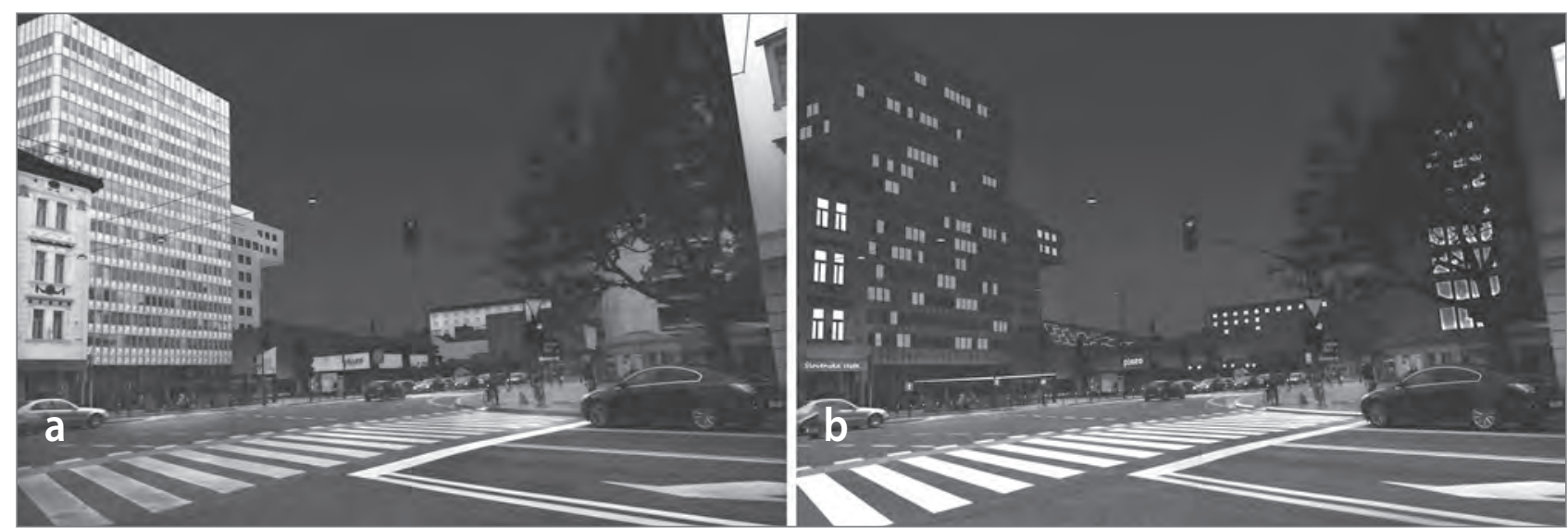

Figure 3: a) Ajdovščina, AK1 plane concept, b) Ajdovščina, AK2 detailed concept (photo and design: Simon Rankel).
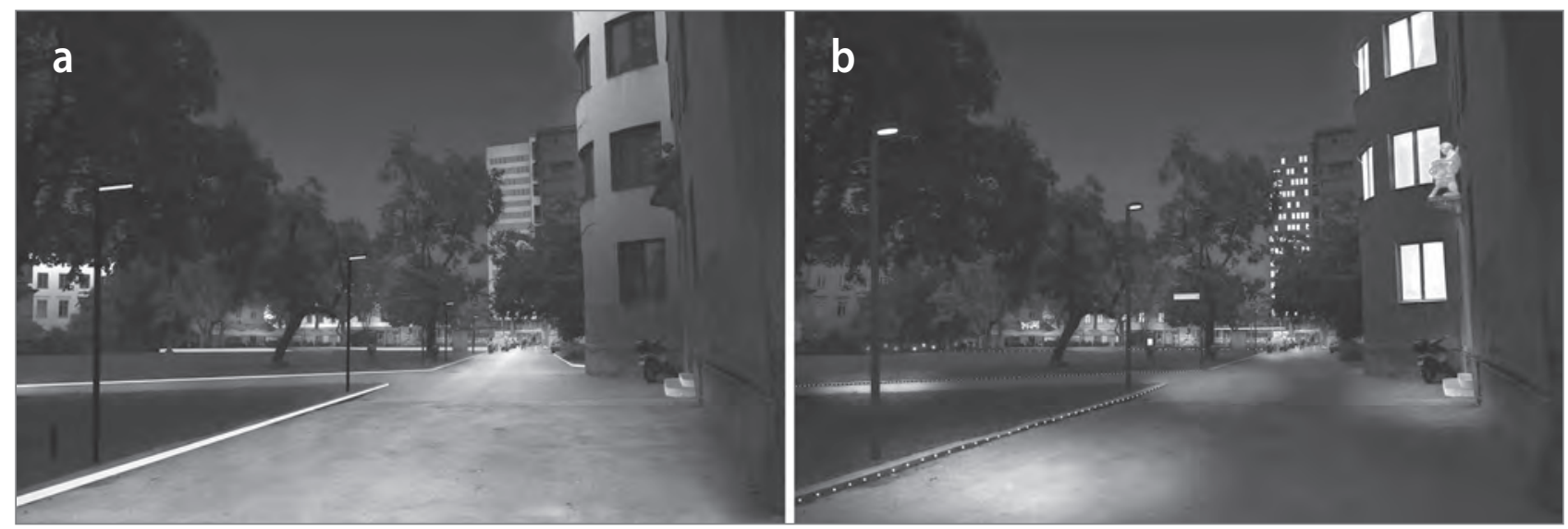

Figure 4: a) Slovenian Reformation Park, PK1 plane concept, b) Slovenian Reformation Park, PK2 detailed concept (photo and design: Simon Rankel).

bers and many smaller illuminated architectural details in the detailed concept. These solutions are represented in the graphic representations. When designing the plane concept for Maria Saal Street (GK1), I attempted to ensure the continuity of the large vertical surfaces of the nearby buildings (Figure 2a). Pleasantly illuminated house façades, discretely illuminated cycle paths and a double separation line on the street ensure that observers take in the complex physical characteristics of urban spaces as a uniform whole. Parts of house façades are accented, and the façade lighting is gradually reduced from the ground upwards. Such lighting would only be turned on during certain evening hours. It would remain off when the city is mostly empty of traffic and pedestrians.

Discrete OLED luminaries applied to a cycle path communicate to motorists and pedestrians that this part of the pavement is intended for cyclists and that special caution must be taken when crossing it. The illumination of this surface is only enough for the eye to sense its difference compared to other parts of the walking paths and roads. In the detailed 


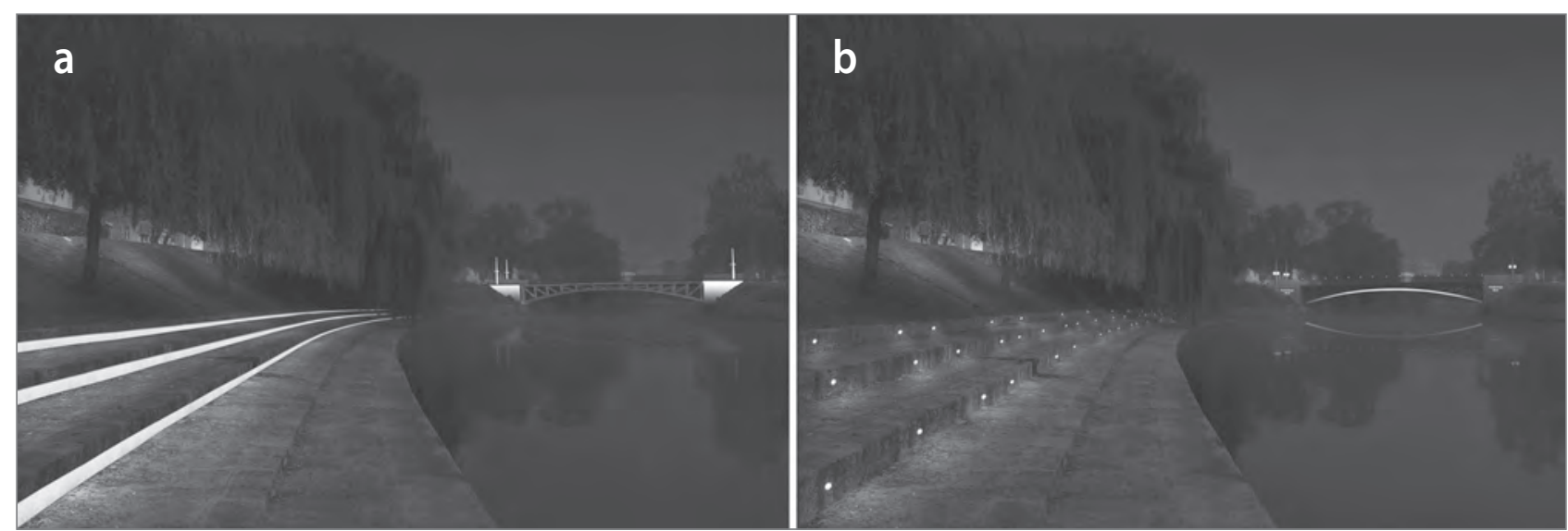

Figure 5: a) Trnovo Quay, TK1 plane concept, b) Trnovo Quay, TK2 detailed concept (photo and design: Simon Rankel).
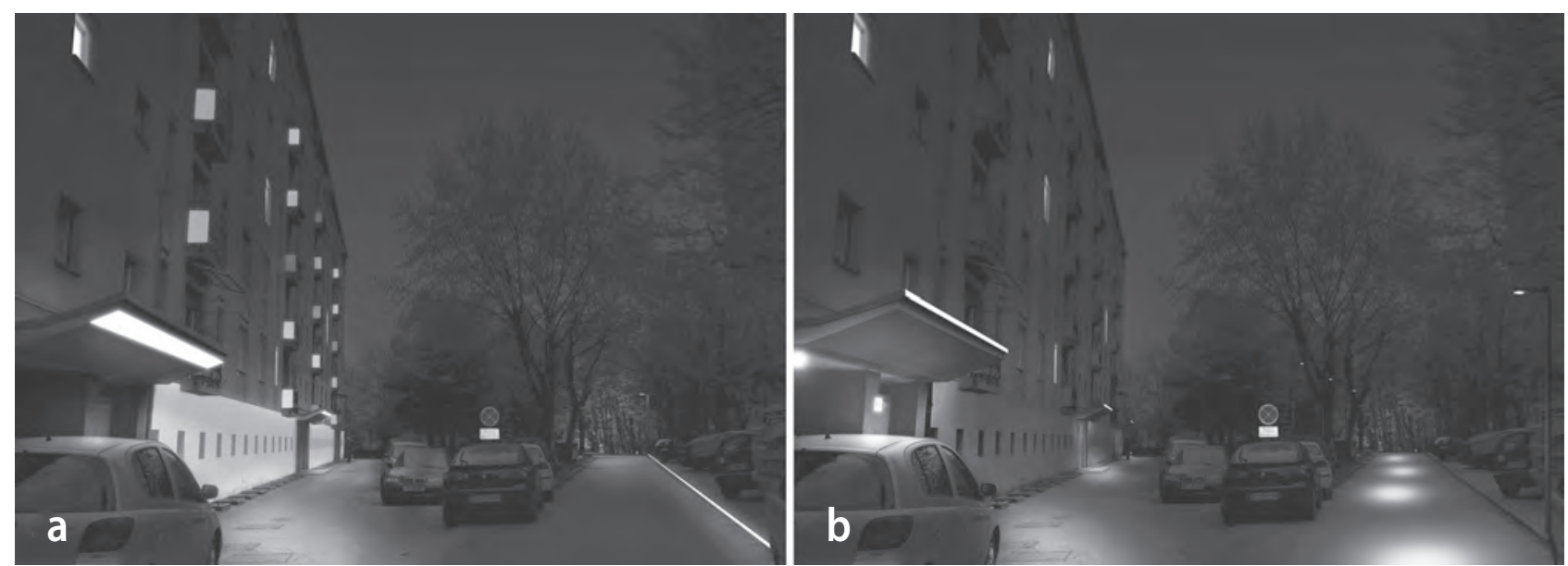

Figure 6: a) Sava Housing Estate: typical residential building, SK1 plane concept, b) Sava Housing Estate: typical residential building, SK2 detailed concept (photo and design: Simon Rankel).

concept (GK2), I attempted to create a continuity of view by repeating the rhythmic spacing of OLED windows and the luminous pavement kerb (Figure 2b). The luminous windows of the Metalka building create a visual frame. The luminous pavement kerbs separate and bring together the elements into a whole at the same time. The illumination of shop windows is kept to a minimum. Emphasis has been placed on lighting the information signs and boards, providing pedestrians and drivers a better overview and facilitating their orientation. The house numbers and street names are moderate light emitters. Some architectural details have also been gently illuminated.

In the plane concept for Ajdovščina (AK1), I have highlighted the visual frame of the field of view by selected luminous building façades (Figure 3a). The luminous façade of the Metalka building is highlighted more than the other buildings. I used large luminous surfaces to make sense of today's fairly chaotic appearance of Ajdovšcina at night. Some surfaces also emit monochromatic light, raising observers' interest. The luminance of today's large and excessively bright advertising billboards is reduced and also depends on the weather conditions. Late at night, the luminous façades are turned off. Only a few smaller surfaces continue emitting light discretely. The detailed concept for Ajdovščina (AK2) builds a visual frame with OLED windows and architectural details (Figure 3b). The underpass, street names, street and road signs are all highlighted. The illumination is based on discrete lighting and a contrast between bright and dark surfaces. Some of the architectural elements of the square are illuminated only as needed; for example, during evening events. Pedestrian crossings are highlighted with built-in OLED luminaries that only turn on when the traffic light is red. In both lighting concepts for Ajdovščina and Maria Saal Street, bars, restaurants and shop windows are less illuminated, allowing me to highlight the differences in the architectural lighting of both concepts.

The plane lighting concept for Slovenian Reformation Park (PK1) focuses on the balanced illumination of walking paths (Figure 4a). The selected bright façades that help emphasise the clarity and simplicity of the park's form create a visual frame. Such OLED luminaries are only placed on certain buildings. Their luminance gradually subsides towards the ground. Highlighted edges contribute to the observer's feeling of orientation. I have discretely highlighted the small stairways in front of the entrances to the residential buildings. The brightness of the luminaries used to illuminate the 
paths through the park is reduced late at night. The correlated colour temperature of the white light they emit can be regulated. The concept is based on purity and clarity. The detailed concept (PK2) highlights the blending of dark and light surfaces (Figure $4 \mathrm{~b}$ ). The surroundings are less illuminated in this concept. The paths are illuminated unevenly. The path kerbs have spot illumination. The architectural elements of the buildings, such as the stone figures above the entrances into the building, are illuminated, as are the street and park name posts. The signs of bars and restaurants are also highlighted. I have attempted to facilitate orientation in the park by using light to highlight the major buildings outside the park. Legibility of space is ensured through the clearly highlighted entrances into the residential buildings, which can be differentiated by applying different colours to the stairs leading to the doors.

The plane concept for Trnovo Quay (TK1) proposes introducing linear OLED luminaries that highlight the clarity of the stone elements of the riverbank (Figure 5a). Multi-linear lighting ensures that the riverbank is perceived as a linked whole. In the distance, the Hradecky Bridge has a dominant illuminated vertical part on the riverbank, which passes into the clearly visible and fully illuminated characteristic pillars of the bridge. The part of the bridge above the Ljubljanica River is illuminated more discretely and thus appears lighter. Together with the lighting of the bridge, the luminous line comprises a visual frame creating the characteristic appearance of this part of the city at night. In the detailed concept (TK2), the line highlight is transferred to the bridge (Figure $5 \mathrm{~b}$ ). This concept thus only highlights its lower arch. The historical significance of the bridge is highlighted with discrete luminous signs showing the name of the bridge. The characteristic lights on the bridge columns remain as they are. As part of the riverbank, the steps are illuminated with spot LED luminaries directed towards the ground. The luminance of the spot luminaries depends on the weather conditions and illumination of the environment and is kept at an acceptably low level at all times. These spot lights appear as an interesting and cosy luminous element that does not degrade this intentionally darker part of the city.

The plane lighting concept for a typical residential building in the Sava Housing Estate (SK1) with OLED luminaries in-

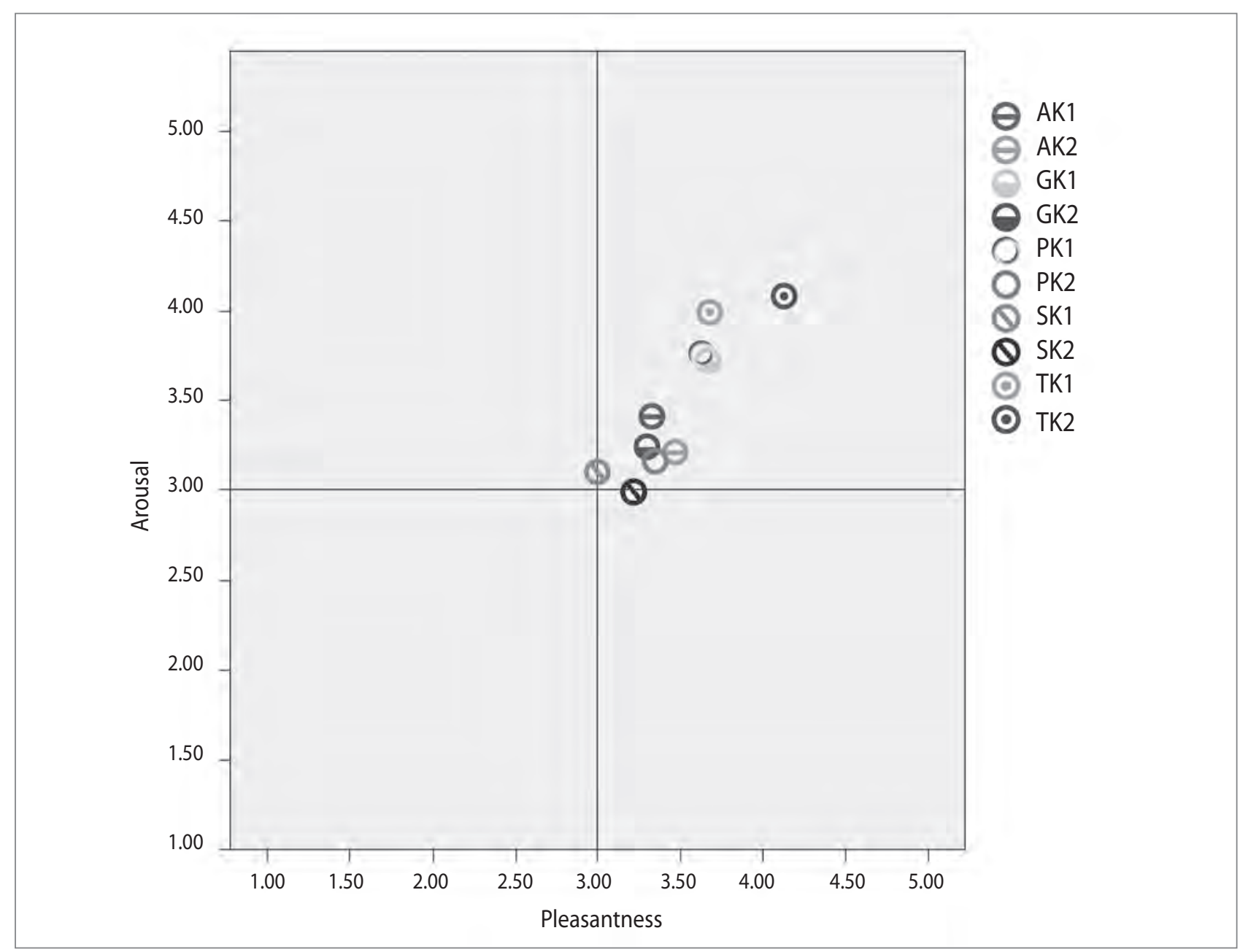

Figure 7: Representation of the average values of the "pleasantness" and "arousal" variables using a 2D graph per concept and location (illustration: Simon Rankel). 
stalled on the bottom part of the building's façade is used as a replacement for lighting used to illuminate the path along the building (Figure 6a). The main OLED lighting of the roof above the entrance would only turn on when a person is detected nearby and would thus enhance the importance of the entrance. They visually match the luminous elements of the vertical surfaces of the balcony fences. The locks and handles of the main entrance doors are gently illuminated, making it easier to open doors. The pavement kerb with built-in OLED luminaries accents the main direction and enhances the feeling of orientation in the space. These luminaries would turn off after a certain time when the neighbourhood attracts only a few visitors or in the winter, when they are covered by snow. The more important crossroads and stairways are gently illuminated, thus enhancing the subjective feeling of safety and ensuring the most important parts are visible at a distance. The detailed lighting concept for a typical residential building (SK2) only emphasises the entrances to the building (Figure 6b). Such lighting is more energy efficient because it is based on highlights and a blending of dark and light surfaces. The entrances are highlighted with linear OLED luminaries attached to the edges of the roof. Luminous house numbers and street names are relocated to more visible positions on the residential building. The few signposts only emit light as needed (when an approaching vehicle is detected in the distance). Walking paths are unevenly illuminated with street LED luminaries. In spite of such illumination, from a distance the path appears as a coherent whole. The decree on limit values due to light pollution (Sln. Uredba o mejnih vrednostih svetlobnega onesnaževanja okolja, Ur. l. RS, no. 81/2007) provides that the operator of façade illumination must ensure the brightness of the illuminated part of the façade calculated as the average value of the full surface of its illuminated part not exceeding $1 \mathrm{~cd} / \mathrm{m}^{2}$. The study assumes that future thin-layer OLED lumi- naries would be treated as a different category of lighting. This would not imply illuminated façades, but instead glowing ones, which however would not be deemed to belong to the same category as advertising billboards. The current regulations do not regulate such a category of luminaries. Such lighting would not be turned on all night, but only in the evening hours and tailored to each selected location. The operating hours would depend on the time of the year and the density of traffic and pedestrians, and the luminance would depend on the weather conditions and the surrounding luminance levels. Any light would be prevented from emitting above the horizon by using advanced thin-layer optics. In addition to their ambient role, OLED luminaries on façades could assume the role of illuminating the nearby ground providing they were positioned appropriately. The share of light reaching the ground from such façades could be regulated, as well as its luminance. This would constitute a new category of hybrid lighting.

\section{Results}

The study was carried out in Slovenian among respondents predominantly living in Slovenia. I also assume that most of the respondents were familiar with the locations featured in the proposals. The graphic representations used in the survey were full colour. The survey sample comprised 528 respondents. Slightly more females were included (53.2\%) than males (46.8\%). After reviewing the descriptive statistics and frequency of distribution of the assessed proposals, I displayed the condensed results of the average values of the "pleasantness" and "arousal" variables in a 2D chart. Both axes divide the chart into four quadrants. Each axis denominates the value 3, which represents an undecided assessment of the variable. The bottom left quadrant shows disagreement with the "pleasantness" and "arousal" statements. The top right quadrant shows

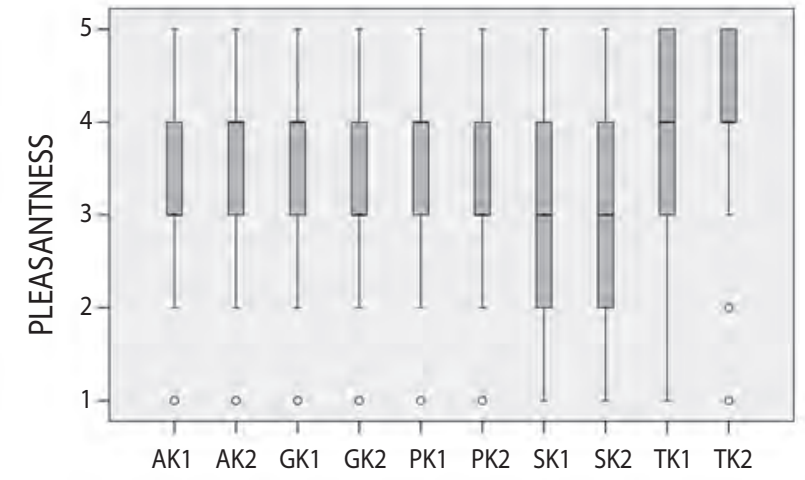

Lighting proposal a

Figure 8: a) Box plots used to illustrate the assessment of the "pleasantness" variable; b) Box plots used to illustrate the assessment of the "arousal" variable (illustration: Simon Rankel).

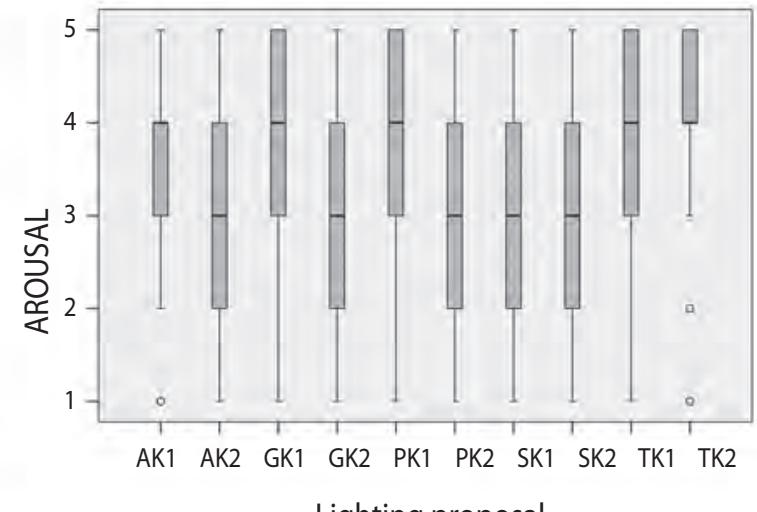

b

Lighting proposal 
Table 1: Comparison of the average assessments of "pleasantness" and "arousal" between both concepts.

\begin{tabular}{lllll}
\hline Variable & Location & Statistical significance & Average 1 & Average 2 \\
\hline Pleasantness & Maria Saal Street & 0.000 & 3.67 (GK1) & 3.31 (GK2) \\
\hline Arousal & Maria Saal Street & 0.000 & 3.73 (GK1) & 3.24 (GK2) \\
\hline Pleasantness & Ajdovščina & 0.010 & 3.33 (AK1) & 3.47 (AK2) \\
\hline Arousal & Ajdovščina & 0.001 & 3.41 (AK1) & 3.21 (AK2) \\
\hline Pleasantness & Slovenian Reformation Park & 0.000 & 3.63 (PK1) & 3.35 (PK2) \\
\hline Arousal & Slovenian Reformation Park & 0.000 & 3.76 (PK1) & 3.16 (PK2) \\
\hline Pleasantness & Trnovo Quay & 0.000 & 3.68 (TK1) & 4.13 (TK2) \\
\hline Pleasantness & Sava Housing Estate & 0.000 & 3.00 (SK1) & 3.22 (SK2) \\
\hline
\end{tabular}

agreement with the "pleasantness" and "arousal" statements. The remaining two quadrants show agreement with one of the two variables.

The results show that most average results of the assessment of the lighting proposals are in the top right quadrant (Figure 7). This can be interpreted as an inclination to agree with the "pleasantness" and "arousal" statements. Only the average results of the assessments of the Sava Housing Estate location are situated near the axes, indicating general indecision on the assessment of each variable. The results of the individual variables can also be displayed using box plots. The box plot of the diagram shows where $50 \%$ of the responses lie. The bold line represents the centre, and small circles are used to represent any outliers.

The diagram of the "pleasantness" variable (Figure 8a) shows that the respondents agree that most lighting proposals are pleasant. Both proposals for Trnovo Quay and the proposals for the residential building in the Sava Housing Estate stand out, because the respondents assess them as being more pleasant and less pleasant than the other proposals. An inclination to agree with the statements for the "arousal" variable (Figure 8) can only be found for Trnovo Quay and the plane concepts for Maria Saal Street and Slovenian Reformation Park. Combining the results of both diagrams confirms the inclination to agree with at least one of the aforementioned variables with respect to all locations and concepts, with the exception of the residential building in the Sava Housing Estate, where half of the assessments of both variables were between 2 and 4. The proposals for Trnovo Quay again stand out: half of the assessments for both variables were between 3 and 5 for the plane concept and as high as between 4 and 5 for the detailed concept. Half of the assessments agreeing with the "pleasantness" of the proposed lighting concepts for Maria Saal Street were between 3 and 4 , whereas half of the assessments agreeing with the "arousal" of both concepts were between 3 and 5 . Half of the respondents rated the plane concept used to illuminate
Ajdovšcina between 3 and 4 for both variables. Most responses rating the detailed lighting concepts for Ajdovščina and Maria Saal Street were between 2 and 4 for the "arousal" variable and between 3 and 4 for the "pleasantness" variable. Except for the assessment of the residential complex in the Sava Housing Estate, all assessments of proposed lighting concepts show that most of the respondents agree with the "pleasantness" and "arousal" statements. Generally speaking, respondents did not find the lighting concept for the residential building in the Sava Housing Estate especially pleasant or arousing, despite the fact that both concepts feature good lighting solutions. These assessments were then compared with the respondents' selection of their favourite and least favourite scenes. The average values for "pleasantness" and "arousal" of both the plane and detailed concept were compared using a paired samples $t$-test. This test was used to determine whether the differences in the statistical values of the assessment of each individual variable for each concept were statistically significant for each location. Because the assessments of both variables are distributed fairly evenly for most proposals, this parametric test can be used. The results show that the differences in the average assessments of individual lighting proposals are great enough and a $95 \%$ probability exits that such differences are statistically significant (or, in another words, a less than $5 \%$ chance exists that the results are random) for most proposals (Table 1).

The $t$-statistics were not 95\% significant with respect to the variable "arousal" for Trnovo Quay (statistical significance: 0.176; averages: $\mathrm{TK} 1=4.00 ; \mathrm{TK} 2=4.07)$ and with respect to the variable "arousal" for the Sava Housing Estate (statistical significance: 0.077 ; averages: SK1 $=3.11$; SK2 $=2.99)$. With respect to the comparison of these two pairs, it is impossible to say with $95 \%$ certainty that the results of assessment of the "arousal" variable differ between the concepts. In the second part of the survey, respondents were asked to give their preferred concept for each city location. I was interested in their opinion of the aesthetic pleasantness, their feelings of visual orientation in the depicted space and the most appropriate 


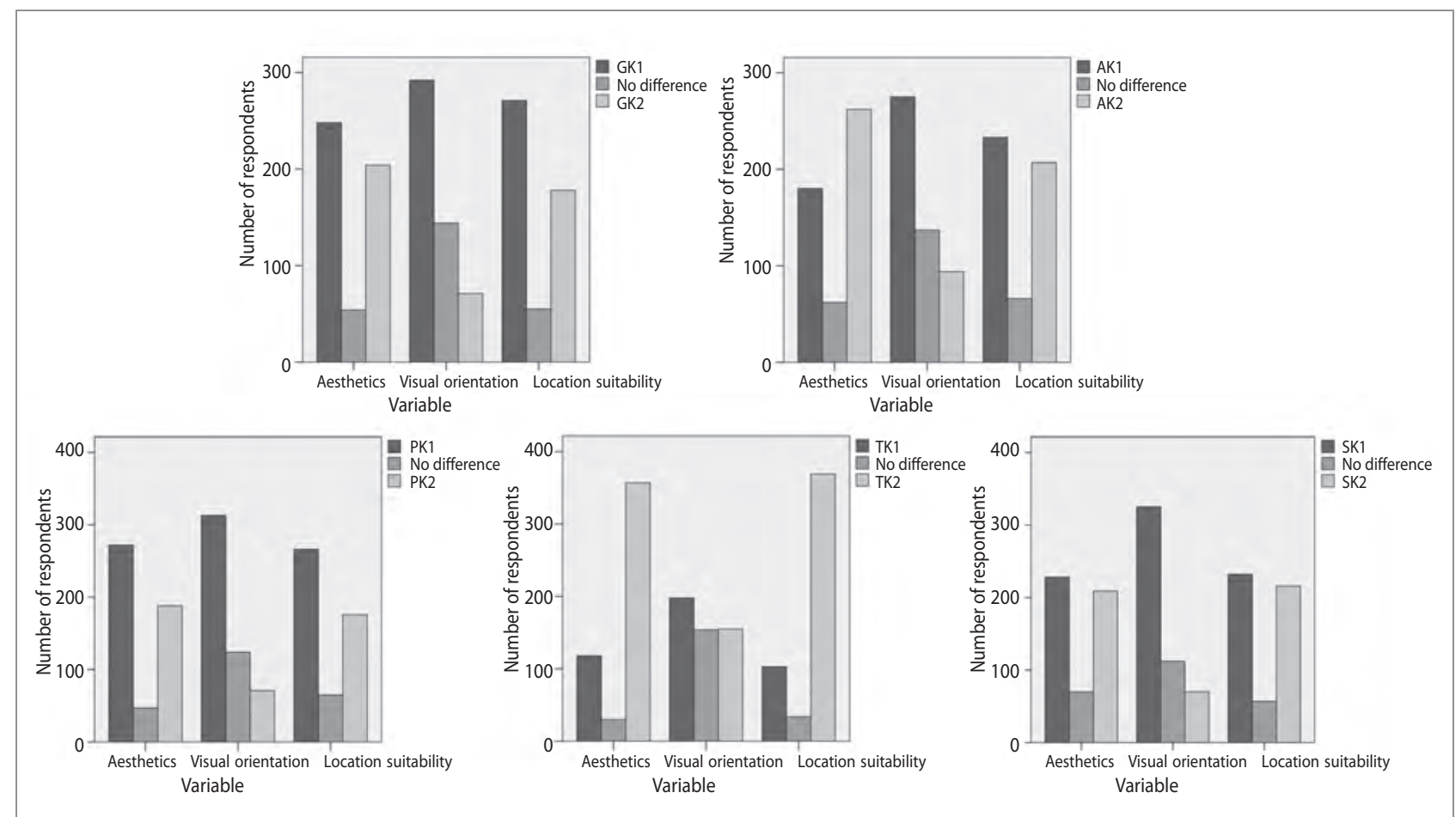

Figure 9: Representation of the selection of the preferred concept for each location (illustration: Simon Rankel).

concept. If a certain respondent felt that both concepts were not sufficiently different with respect to a certain variable, the response stating that there is no difference between the proposed concepts was available. For Maria Saal Street, Slovenian Reformation Park and the Sava Housing Estate, most respondents selected the plane concept for all of the observed variables (Figure 9).

Selecting the plane concept was significant for the visual orientation variable in most locations. Only in the case of Trnovo Quay were the results of selecting between the options for this variable fairly balanced. With respect to aesthetics, the selection of the detailed concept for Trnovo Quay and Ajdovšcina and the selection of the plane concept for Slovenian Reformation Park stand out. The responses for Maria Saal Street and the residential complex at the Sava Housing Estate were fairly equally distributed, with a slight preference for the plane concept. Most respondents felt the detailed concept including the spot lighting of the riverbank and the soft lighting of the Hradecky Bridge was the more aesthetic. Respondents were very positive about this lighting proposal. This is also illustrated by the very positive assessment of "pleasantness" and "arousal" in the first part of the survey. The results of the selection of the most appropriate concept for the given location are very similar to the results for aesthetics. The plane concept for Maria Saal Street and Slovenian Reformation Park and the detailed concept for Trnovo Quay and Ajdovščina prevailed. Comparison of the results of this part of the survey with the first part reveals a high level of coherence, especially with respect to
Maria Saal Street, Slovenian Reformation Park and Trnovo Quay. Their more favourable assessments in light of "pleasantness" and "arousal" comply with the concept selection and the assessment of its appropriateness to the location in question. At the end of the survey, I asked respondents to select two of the scenes of the proposed lighting they liked the most and two they liked the least. Nearly $60 \%$ of all respondents selected the detailed concept for Trnovo Quay as their favourite scene, followed by the plane concept for Trnovo Quay (17\%). The remaining proposals were selected much less frequently. The second most favourite images are the lighting of both parks, followed by the plane concept for Trnovo Quay and Maria Saal Street. Most respondents selected the detailed concept for the Sava Housing Estate as their least favourite image, followed by the plane concept for the same area and for Ajdovsčina. I believe that the location affected the respondents' selection of their favourite scene. This also affects their opinion of the pleasantness and arousal of the lighting of each location.

\section{Discussion}

The study illustrates that, on average, in their assessment of the affective quality of graphic representations of future lighting solutions, the respondents agree with the statements on the feelings of "pleasantness" and "arousal". This applies to all locations discussed and to both variables at the same time. The only exceptions are the assessment of the "pleasantness" of the plane lighting solution and the assessment of the "arousal" of 
the detailed lighting solution of the residential building and its surroundings in the Sava Housing Estate. In both cases, on average, the assessments of the respondents were undecided. This confirms the impact of the location on respondents' selection of their least favourite scenes and thus also on their assessment of the proposals. The same influence was also noted with respect to the positive assessment of both lighting proposals for Trnovo Quay. I also found that the respondents felt that the plane concept was more pleasant when applied to more densely built-up city centre locations such as Maria Saal Street. The reason for this most likely lies in the large bright surfaces that allow observers to perceive what is a fairly complex space as a whole. However, such wholes must not be too large and there must not be too many of them. This was confirmed by the case of Ajdovsčina, where most of the respondents did not find the plane concept very favourable. The detailed concepts received better "pleasantness" assessments in locations not strictly in the city centre, which are better suited to more discreet illumination. These scenes have more natural elements such as water and foliage. I found that the plane concept would be better assessed from the point of view of arousal at all significantly assessed proposal concept pairs. The results confirm that the overuse of new lighting possibilities can be aesthetically less pleasing. The respondents assessed the detailed lighting proposal of Slovenian Reformation Park less favourably because they find the more uniform and coherent plane concept more pleasant. This confirms the findings of the existing literature and the results of prior research. Ünver (2009) confirms that contrast criteria heavily influence the perception of the illumination of urban parks. An uneven distribution of light and strong shadows can create an overly dramatic effect and result in an unpleasant look of the landscape. As an architectural element, shadows significantly affect the way humans perceive and experience space (Kastelic et al., 2012). Maria Johansson et al. (2011) found that visitors must find paths in the park sufficiently illuminated both from the point of view of visual accessibility as well as from the point of view of "pleasantness" in order to assess any lighting as appropriate. Research shows that the use of appropriate LED retrofits can also help improve both criteria (Kuhn et al., 2013). The reason the plane concept for the park was selected over the detailed concept as the most appropriate may lie in the appearance of the OLED windows. These probably give the observer the feeling of separation of "inner" and "outer" city life and have no role in improving the city's appearance. I found that in most locations the plane concept was characteristically selected with respect to the "visual orientation" variable. Only in the case of Trnovo Quay were the results of selecting between the concepts for this variable fairly balanced. The reason most likely lies in the fact that the plane concept is generally brighter and more uniform. The literature characterises the "visual accessibility" variable with the visual field, environmen- tal trust and the feeling of brightness (Johansson et al., 2011). This can explain the connection between the feeling of brightness of the lighting proposals and the perception of visual orientation in spaces illuminated in such a manner. In actual space, people receive spatial information through their peripheral ("retinal") vision (Liljefors, 1999), whereas looking at images mostly activates central vision, which provides information about details. Thus the "visual orientation in an illuminated space" variable discussed herein only conveys an opinion on the visual clarity of the illumination concepts visually presented. Because computer monitor technologies differ, the possibility that respondents used monitors with differing brightness to complete the survey should be stressed. Furthermore, it is also likely that the respondents applied different brightness settings to their monitors and were located in differently illuminated rooms while completing the survey. To a minor extent, these factors may have affected the assessed "pleasantness" and "arousal" of the lighting proposals. It is due to these factors that this article does not discuss the impact of the "correlated colour temperature" variable on the assessment of the future lighting proposals. In their study, Casciani and Rossi (2012) found that, in terms of "pleasantness" and "arousal", cases that depict an unusual approach to lighting the space in question and that actively engage users were assessed most favourably. This therefore proves the increasing need of users to experience cities in light of their social contacts. Like Ünver (2009), they both note the significant impact colour has on one's assessment of lighting pleasantness. Although LED and OLED lighting show strong potential in terms of the use of single-colour light, I intentionally avoided them in the context of studying future lighting proposals. Usually, the initial interest in colour lighting rapidly subsides. Because users also grow tired of such illumination more quickly, it is only recommended for short-term, decorative purposes. The assessment of the "aesthetic" and "appropriateness" variables confirm their fair degree of correlation. The only exception is the lighting proposal for Ajdovšcina, for which most respondents thought the detailed concept was more aesthetic, but believed the plane concept was more appropriate. The aesthetic variable is most pronounced in the respondents' preference for the detailed lighting concept for the Trnovo Quay location. Aesthetic assessment requires the interpretation and categorisation of what one can observe, and thus transcends mere emotional responses (see Veitch, 2001). Stephen Kaplan (1979) describes his functional approach to landscape aesthetics by evaluating the dimensions of coherence, legibility, mystery and complexity. An appropriate combination of these dimensions is the most likely explanation for the overwhelmingly positive reception of the proposed lighting for Trnovo Quay. New ways of using LED- and OLED-based luminaries can result in a greater number of applications, which may result in more electricity spent, higher costs and greater environmental pollution. Installing 
OLED luminaries on the façades of buildings would be no easy task. Although no façade is completely flat, combining individual OLED modules to provide the appropriate luminous intensity and colour of light emitted would also prove extremely difficult. Namely, the luminous flux of single modules falls differently and irregularly, meaning that high-quality control electronics would have to regulate both parameters. This is no easy task because the human eye can detect minor differences in contrast, which do not depend only on the luminance of the source, but also on the spectral distribution of light emitted. It would be very difficult to maintain such a system. More widespread future use of OLED functional ambient luminaries for outdoor surfaces will probably begin with OLED devices highlighting details such as house numbers and street names. The development and positioning of LED and OLED lighting in urban spaces must also comply with the principles of mesopic photometry (see, e.g., Ylinen, et al., 2010) because only this can provide for more energy and visually efficient outdoor lighting. The problem posed by light pollution should also be considered when positioning luminaries in urban spaces. This mainly refers to the problem of the general over-illumination of urban spaces at night, the problem of excess light leaking into the skies and surroundings, glare and using light sources with appropriate spectral characteristics. Research shows that outdoor lighting affects the circadian system in which humans generate melatonin (Rea et al., 2010). In a practical application, this effect is most easily observed in the use of very "cold white" light sources. White light LED sources that have an expressed peak of spectral power distribution in a shorter wavelength range compared to high-pressure sodium lamps can increase sky glow by between 10 and $20 \%$ (Bierman, 2012). However, today quality and efficient LED light sources that emit light with low correlated colour temperatures (a "warm white") are available. Some more recent research has also studied the impact of spectral distribution of luminous surrounds on LED discomfort glare perception (see Sweater-Hickcox et al., 2013). The smart regulation of solid-state light sources could contribute to their greater energy efficiency and to reducing the amount of light pollution.

This article emphasises the need to take a more comprehensive approach to the significance of illuminating cities when adopting new technologies and taking advantage of any such transition to improve the appearance of the city. Only the coherent, well thought-out and innovative positioning of LED and OLED luminaries in the urban environment appropriate to the specific location can positively impact the appearance of the city in the opinion of its users. The research results can serve as a starting point for further studies of the innovative and feasible application of new lighting technologies in urban environments. This article is part of a broader study in which, among other things, I also studied how respondents' ages af- fected their assessments of variables and lighting proposals. I also strove to discern whether the respondents would assess the proposed concepts differently when the concept solutions were illustrated with larger images and explained in more detail. In addition, I conducted a predictive comparative framework analysis of the electricity used by the future lighting concepts for the particular locations.

\section{Conclusion}

This article presents the first example of a study of future LEDand OLED-based lighting and its impact on the appearance of a city at night. It thus contributes to the theory of illuminating urban spaces through its specific interdisciplinary approach. This approach combines innovative technical and architectural aspects with a public opinion survey based on the theoretical foundations of environmental psychology. The results show that the proposed use of solid-state lighting solutions in most of the locations discussed would, on average, positively affect the perceived appearance of illuminated urban spaces, whereas there are statistically significant differences between the assessment of the "pleasantness" and "arousal" of both concepts for each lighting proposal. This article has succeeded in answering the main research question. However, one must also consider the other effects ascertained, such as the impact of the location on the respondents' assessments, the initial assumptions and the limitations of the research method used. I would like to stress once again that both concepts for the proposed lighting attempt to improve the connection between the compositive unity of the space and rebuild the structural characteristics of the city. Installing new lighting technologies can contribute to improving the appearance of the city at night, as long as it complies with the aesthetic principles of urban lighting expressed in the balanced system of spatial hierarchies and differences (Brandi \& Geissmar-Brandi, 2007), and as long it is adequate to the urban location and city identity. Future research could focus on implementing a single type of solid-state lighting solution and comparing its effect on different locations. Opinions on the appearance of the city could also be studied by comparing its existing and future lighting. Once it is technologically feasible, I will be able to study the impact of the innovative positioning of OLED luminaries in real-life urban spaces. The possibilities of using LED and OLED lighting in urban spaces are truly vast, although all possibilities are neither always justified nor acceptable when taking into consideration the many other characteristics, needs and requirements of urban light planning. Designing sustainable urban lighting solutions that can enhance the positive impact of new lighting technologies on cities and their users and reduce their negative effects, and at the same contribute to designing the future appearance of cities at night, is conditional upon pru- 
dent planning that considers the factors of various fields of urban lighting.

\section{Simon Rankel}

University of Ljubljana, Faculty of Civil and Geodetic Engineering, interdisciplinary doctoral student in spatial and urban planning, Slovenia

E-mail: simon.rankel@siol.net

\section{References}

Ab Jalil, N., Yunus, R. M. \& Said, N. S. (2012) Environmental colour impact upon human behaviour: A review. In: Abbas, M. Y., Bajunid, A. F. I. \& Azhari, N. F. N. (eds.) Proceedings of Asia Pacific Conference on Environment-Behaviour Studies, pp. 54-62. Farmagusta, Procedia - Social and Behavioral Sciences.

Bačlija, I. (2011) Urban management in a European context. Urbani izziv, 22(2), pp. 137-146. DOI: 10.5379/urbani-izziv-en-2011-22-02-006

Bandur, S. (2012) Podhod Ajdovščina - kronično pozabljeno podzemlje. Delo, 54(10), 12 Jan. 2012.

Bierman, A. (2012) Will switching to LED outdoor lighting increase sky glow? Lighting Research and Technology, 44(4), pp. 449-458. DOI: $10.1177 / 1477153512437147$

Bizjak, I. (2012) Improving public participation in spatial planning with Web 2.0 tools. Urbani izziv, 23(1), pp. 112-124. DOI: 10.5379/urbaniizziv-en-2012-23-01-004

Brandi, U. \& Geissmar-Brandi, C. (2007) Light for cities, lighting design for urban spaces. A Handbook. Hamburg, Birkhäuser.

Casciani, D. \& Rossi, M. (2012) ELSE, Experience of lighting sustainability in the environment. Paper presented at the Cumulus Conference Northern World Mandate - Towards Open and Participative Cities, 24-26 May, Helsinki, Finland. Typescript.

Chiang, C., Winscom, C., Bull, S. \& Monkman, A. (2009) Mechanical modeling of flexible OLED devices. Organic Electronics, 10(7), pp. 1268-1274. DOI: 10.1016/j.orgel.2009.07.003

Flynn, J. E., Hendrick, C., Spencer, T. \& Martyniuk, O. (1979) A guide to methodology procedures for measuring subjective impressions in lighting. Journal of IES, 8(2), pp. 95-110.

Gardner, C. (2006) The use and misuse of coloured light in the urban environment. Optics \& Laser Technology, 38(4-6), pp: 366-376. DOI: 10.1016/j.optlastec.2005.06.022

Gibson, J. J. (1971) The information available in pictures. Leonardo, 4(1), pp. 27-35. DOI: 10.2307/1572228

Grover, R., Srivastava, R., Omwati, R., Mehta, D. S. \& Kamalasanan, M. N. (2011) New organic thin-film encapsulation for organic light emitting diodes. Journal of Encapsulation and Adsorption Sciences, 1(2), pp. 23-28. DOI: 10.4236/jeas.2011.11003

Ho, D. C. W., Yau, Y., Law, Poon, S. W., Yip, H. K. \& Liusman, E. (2012) Social sustainability in urban renewal: An assessment of community aspirations. Urbani izziv 23(1), pp. 125-139. DOI: 10.5379/urbani-izziven-2012-23-01-005

Hohl-Abi Chedid, A. (2012) Philips provides OLED outlook at the LED show. LEDs Magazine industry news, 31 Jul. 2012. Available at: http:// ledsmagazine.com (accesed 22 Oct. 2012).

Joels, D. (2006) Lighting design for urban spaces: Connecting light qualities and urban planning concepts. Master's dissertation. Stockholm, KTH Royal Institute of Technology, School of Technology and Health, Architectural Lighting Design.
Johansson, M., Pedersen, E., Maleetipwan-Mattson, P., Kuhn, L. \& Laike, T. (2013) Perceived outdoor lighting quality (POLQ): A lighting assessment tool. Journal of Environmental Psychology. DOI: 10.1016/ j.jenvp.2013.12.002

Johansson, M., Rosén, M. \& Küller, R. (2011) Individual factors influencing the assessment of the outdoor lighting of an urban footpath. Lighting Research and Technology, 43(1), pp. 31-43. DOI: $10.1177 / 1477153510370757$

Kaplan, S. (1979) Perceptions and Landscape: Conceptions and Misconceptions. In: Elsner, G. H. \& Smardon, R. C. (eds.) Proceedings of Our national landscape, pp. 241-248. Incline Village, NV, United States Department of Agriculture.

Kastelic, J., Novljan, T. \& Vodopivec, A. (2012) Učinek sence pri snovanju, zaznavanju in doživljanju arhitekturnega prostora [The shadow effect in the conception, perception and experience of architectural space]. AR ahitektura, raziskave, 2-3, pp. 18-27.

Kennedy, J. M. (1974) A psychology of picture perception. San Francisco, Jossey-Bass Publishers.

Kennedy, S. (2005) Escaping the bulb culture: The future of LEDs in architectural illumination. LEDs Magazine, 1(1), pp. 13-15.

Kim, I., Choi, A. \& Jeong, J. (2012) Precise control of a correlated color temperature tunable luminaire for a suitable environment. Building and Environment, 57, pp. 302-312. DOI: 10.1016/j.buildenv.2012.06.001

Kostic, A. \& Djokic, L. (2013) Subjective impressions under LED and metal halide lighting. Lighting Research and Technology. DOI: $10.1177 / 1477153513481037$

Kuhn, L., Johansson, M., Laike, T. \& Govén, T. (2013) Residents' perceptions following retrofitting of residential area outdoor lighting with LEDs. Lighting Research and Technology, 45(5), pp. 568-584. DOI: $10.1177 / 1477153512464968$

Küller, R., Ballal, S., Laike, T., Mikellides, B. \& Tonello, G. (2006) The impact of light and colour on psychological mood: A cross-cultural study of indoor work environments. Ergonomics, 49(14), pp. 1496-1507. DOI: 10.1080/00140130600858142

Lee, J., Hofmann, S., Furno, M., Thomschke, M., Kim, Y. H., Lüssem, B. \& Leo, K. (2011) Systematic investigation of transparent organic light-emitting diodes depending on top metal electrode thickness. Organic Electronics, 12(8), pp. 1383-1388. DOI: 10.1016/j.orgel.2011.05.006

Legge, G. E., Yu, D., Kallie, C. S., Bochsler, T. M. \& Gage, R. (2010) Visual accessibility of ramps and steps. Journal of Vision, 10(11), pp. 1-19. DOI: $10.1167 / 10.11 .8$

Liljefors, A. (1999) Lighting - visually and physically. Stockholm, KTH Lighting Department.

Lynch, K. (2010) Podoba mesta (The image of the city). Novo Mesto, Založba Goga.

Mayhoub, M. S. \& Carter, D. J. (2012) Hybrid lighting systems: Performance and design. Lighting Research and Technology, 44(3), pp. 261276. DOI: $10.1177 / 1477153511416324$

McKinsey and Company (2012) Lighting the way: Perspectives on the global lighting market. Vienna, McKinsey and Company.

Neumann, A., Wierer, J. J., Jr., Davis, W., Ohno, Y., Brueck, S. R. J. \& Tsao, J. Y. (2011) Four-color laser white illuminant demonstrating high color-rendering quality. Optics Express, 19(S4), pp. A982-A990. DOI: 10.1364/OE.19.00A982

Novljan, T. (2008) Svetlobno degradirani arhitekturni ambienti [Architectural ambiences degraded by illumination]. AR ahitektura, raziskave, 9(2), pp. 86-91.

Odlok o razglasitvi spomenikov naravne in kulturne dediščine na območju 
občine Ljubljana Center med Aškerčevo, Tivolsko in Slovensko cesto. Uradni list Republike Slovenije, no. 60/1993. Ljubljana.

Parandian, A. \& Rip, A. (2013) Scenarios to explore the futures of the emerging technology of organic and large area electronics. European Journal of Futures Research, 15(9), pp. 1-18. DOI: 10.1007/s40309-0130009-2

Prosenc, D. M. \& Potočnik, T. (2011) Konservatorski načrt za prenovo Aškerčeva, Tivolska, Slovenska (OPPN 106 - Kolizej) v Ljubljani. Project assignment. Ljubljana, Populus Prostorski inženiring d.o.o.

Rea, M. S., Bullough, J. D. \& Akashi, Y. (2009) Several views of metal halide and high-pressure sodium lighting for outdoor applications. Lighting Research and Technology, 41(1), pp. 297-320. DOI: 10.1177/1477153509102342

Rea, M. S., Smith, A., Bierman, A. \& Figueiro, M. G. (2010) The potential of outdoor lighting for stimulating the human circadian system. Research report. Troy, NY, Lighting Research Center, Rensselaer Polytechnic Institute.

Rehan, R. M. (2013) Sustainable streetscape as an effective tool in sustainable urban design. HBRC Journal, 9(2), pp. 173-186. DOI: 10.1016/ j.hbrcj.2013.03.001

Russell, J. A. (1980) A circumplex model of affect. Journal of Personality and Social Psychology, 39(6), pp. 1161-1178. DOI: 10.1037/h0077714

Russell, J. A. (2003) Core affect and the psychological construction of emotion. Psychological Review, 110(1), pp. 145-172. DOI: 10.1037/0033295X.110.1.145

Sašek Divjak, M. (2008) Urban planning for the strategic spatial development of Ljubljana. Urbani izziv, 19(1), pp. 133-145. DOI: 10.5379/ urbani-izziv-en-2008-19-01-002

Schmidt, J. A. \& Töllner, M. (2006) Stadtlicht, Lichtkonzepte für die Stadgestaltung. Stuttgart, Fraunhofer IRB Verlag.

Schwamb, P., Reusch, T. C. G. \& Brabec, J. (2013) Passive cooling of large-area organic light-emitting diodes. Organic Electronics, 14(8), pp. 1939-1945. DOI: 10.1016/j.orgel.2013.04.023

Slawinski, M., Wingarten, M., Heuken, M., Vescan, A. \& Kalisch, H. (2013) Investigation of large-area OLED devices with various grid geometries. Organic Electronics, 14(10), pp. 2387-2391. DOI: 10.1016/ j.orgel.2013.06.003

Sweater-Hickcox, K., Narendran, N., Bullough, J. D. \& Freyssinier, J. P. (2013) Effect of different coloured luminous surrounds on LED discomfort glare perception. Lighting Research and Technology, 45(4), pp. 464-475. DOI: 10.1177/1477153512474450

Ünver, A. (2009) People's experience of urban lighting in public space. Master's dissertation. Ankara, Middle East Technical University, City and regional planning.

Uredba o mejnih vrednostih svetlobnega onesnaževanja okolja. Uradni list Republike Slovenije, no. 81/2007. Ljubljana.

Veitch, J. A. (2001) Psychological processes influencing lighting quality. Journal of the Illuminating Engineering Society, 30(1), pp. 124-140. DOI: 10.1080/00994480.2001.10748341

Ylinen, A., Puolakka, M. \& Halonen, L. (2010) Impact of mesopic design on outdoor lighting energy efficiency. In: Proceedings of CIE 2010 Lighting quality and energy efficiency, pp. 475-481. Vienna, Commission Internationale de L'Eclairage.

Zakon o varstvu kulturne dediščine. Uradni list Republike Slovenije, no. 16/2008. Ljubljana. 